3. Cohen-Tannoudji, C., Diu, B. \& Laloë, F. Quantum Mechanics 412 (Wiley, New York, 1977).

4. Mollow, B. R. Phys. Rev. 188, 1969-1975 (1969).

5. Mücke, O. D., Tritschler, T., Wegener, M., Morgner, U. \& Kärtner, F. X. Phys. Rev. Lett. 87, 57401 (2001).

6. Mücke, O. D., Tritschler, T., Wegener, M., Morgner, U. \& Kärtner, F. X. Opt. Lett. 27, 2127-2129 (2002).
7. Udem, T., Holzwarth, R. \& Hänsch, T. W. Nature 416, 233-237 (2002).

8. Brabec, T. \& Krausz, F. Rev. Mod. Phys. 72, 545-591 (2000).

9. Paulus, G. G. et al. Nature 414, 182-184 (2001).

10. Ramond, T. M., Diddams, S. A., Hollberg, L. \& Bartels, A. Opt. Lett. 27, 1842-1844 (2002).

11. Morgner, U. et al. Phys. Rev. Lett. 86, 5462-5465 (2001).

Conservation biology

\title{
Lone wolf to the rescue
}

\author{
Pär K. Ingvarsson
}

Genetic analysis has revealed how a small and isolated population of grey wolves found salvation in the form of the genetic variation offered by a single, immigrant male.

$\mathrm{H}$ uman influence has led to the decline of many animal species and fragmentation of their populations. One consequence is loss of their genetic diversity. But how does this loss affect endangered species? Some have argued that it is only a minor threat to survival, because small populations are more vulnerable to demographic or environmental effects - for example, chance events affecting the birth and death of individuals, or atypical weather conditions such as an unusually cold winter. Others believe that a lack of genetic diversity increases the risk of inbreeding, which may ultimately drive a species to extinction because inbred organisms have reduced survival and fecundity.

Immigration from surrounding areas may prevent the extinction of small populations by increasing their size. Alternatively, genetic rescue - replenishing genetic variation and reducing the consequences of inbreeding - could have the same effect. A paper by Vilà et al. ${ }^{1}$, published last month by Proceedings of the Royal Society, lends strong support to the view that genetic rescue does occur $^{2}$. The authors provide compelling evidence that the current Scandinavian population of the grey wolf (Canis lupis; Fig. 1) was for a long time limited in size by lack of genetic diversity. Furthermore, the authors

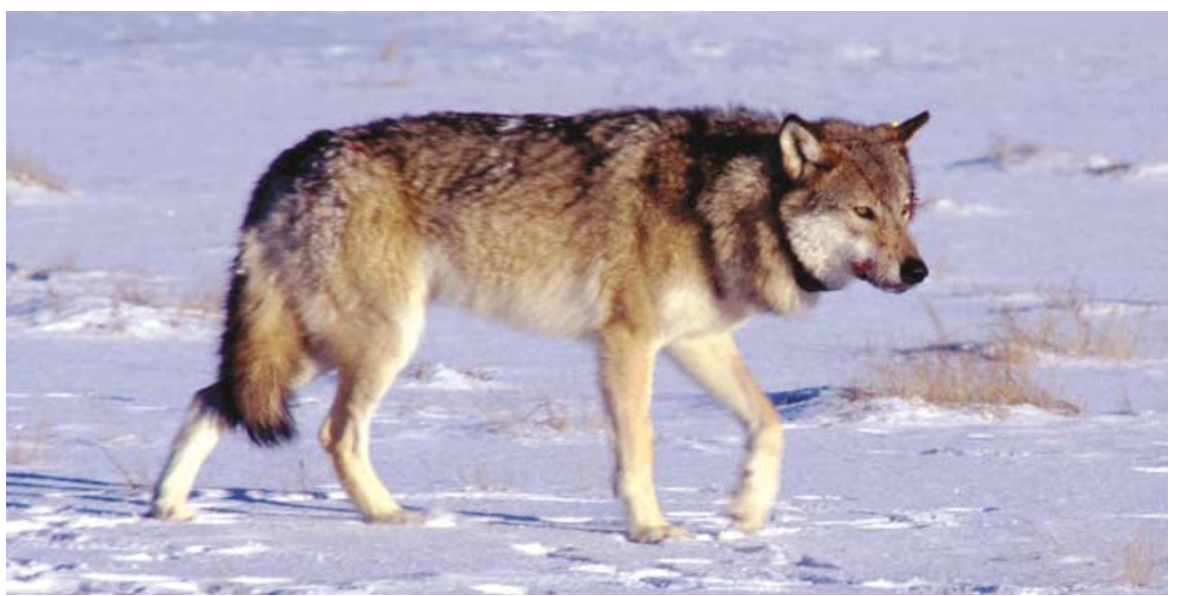

Figure 1 A Scandinavian wolf in the wild. Additional genetic variety has turned out to be the spice of life for the population concerned.

show that the steady increase in that population over the past decade started with the arrival of a single immigrant wolf.

Scandinavian grey wolves were decimated during the nineteenth and twentieth centuries, largely through hunting and poisoning. This population was finally considered to be extinct in the 1960s. But in the early 1980s, a single breeding pack was once again established in southern Scandinavia, about $1,000 \mathrm{~km}$ from the nearest known populations in Finland and Russia. The pack remained small, consisting of around ten animals, for several years. It was monitored from its initial establishment, and genetic data showed that a single male and female were the founding members. Moreover, the population suffered from inbreeding and declining levels of genetic variation over time. At the same time, studies of captive wolves indicated that birth defects, such as hereditary blindness, were common for levels of inbreeding similar to those observed in the wild population ${ }^{3,4}$.

Suddenly, in 1991, the Scandinavian wolf population started to increase and now numbers $10-11$ breeding packs, totalling about 100 wolves. From the genetic data obtained by Vilà and colleagues ${ }^{1}$, it is evident that the increase corresponds with the immigration of a single male wolf of Finnish or

Siberian origin. Coinciding with the arrival of this male, much of the genetic diversity that had been lost from the population was restored. Vilà et al. show that of the 72 wolves born after 1993, 68 can trace at least part of their ancestry to the immigrant male of 1991. This male has had a disproportionately large influence on the genetic make-up of the present Scandinavian wolf population, implying that natural selection ${ }^{5}$ has driven the rapid increase in numbers.

The authors hint at a possible cause for the extraordinary reproductive success of the immigrant male. Many species have behavioural mechanisms that prevent matings between close relatives to avoid the deleterious effects of inbreeding, and wolves are no exception. So these mechanisms may have contributed to the low birth rate in the original breeding pack and thus prevented the population from expanding. With the input of new genetic variation from the immigrant, the potential for matings between unrelated animals was considerably increased.

The study by Vilà et al. ${ }^{1}$ follows others ${ }^{6,7}$ in suggesting that low levels of migration between populations of endangered species (either natural, or directed through relocation programmes) can be extremely effective in restoring genetic diversity and reducing the risk of extinction through inbreeding. But a cautionary note is needed here. In relocation programmes, it is essential that the animals are not moved to environments to which they are not adapted. Such action could actually increase the risk of extinction through a process known as outbreeding depression $^{8}$, where offspring between animals adapted to different conditions have lower survival rates and lower fecundity in both parental environments because they are not adapted to either of them. Animals for relocation should be chosen from environments that are as similar as possible to their new habitat.

The relative merits of genetics and ecology as factors in understanding the risks of extinction continue to be debated. The study by Vilà et al. is a refreshing reminder of how important it is to combine both perspectives toward understanding what is required to preserve Earth's biodiversity.

Pär K. Ingvarsson is in the Department of Ecology and Environmental Sciences, University of Umeå, SE-901 87 Umeå, Sweden.

e-mail: pelle@eg.umu.se

1. Vilà, C. et al. Proc. R. Soc. Lond. B 10.1098/rspb.2002.2184 (2002).

2. Ingvarsson, P. K. Trends Ecol. Evol. 16, 62-63 (2001).

3. Ellegren, H. Hereditas 130, 239-244 (1999).

4. Laikre, L. \& Ryman, N. Conserv. Biol. 5, 33-40 (1991).

5. Ingvarsson, P. K. \& Whitlock, M. C. Proc. R. Soc. Lond. B 267, 1321-1326 (2000).

6. Madsen, T., Shine, R., Olsson, M. \& Wittzell, H. Nature 402, 34-35 (1999).

7. Westemeier, R. L. et al. Science 282, 1695-1698 (1998).

8. Shields, W. M. in The Natural History of Inbreeding and Outbreeding (ed. Thornhill, N. W.) 143-169 (Univ. Chicago Press, 1993). 